\title{
Triple-c Cartilage Tympanoplasty: Case Series
}

\author{
Kartik Parelkar, Smita Nagle, Mohan Jagade, Vandana Thorawade, Poonam Khairnar, \\ Anoop Attakil, Madhavi Pandare, Rajanala Nataraj, Reshma Hanwate, Rajesh Kar \\ Department of ENT, Grant Govt Medical College \& Sir J J Group of Hospitals, Mumbai, India \\ Email: kartikparelkar@ymail.com
}

Received 20 December 2014; accepted 7 January 2015; published 16 January 2015

Copyright (C) 2015 by authors and Scientific Research Publishing Inc.

This work is licensed under the Creative Commons Attribution International License (CC BY). http://creativecommons.org/licenses/by/4.0/

(c) $\underset{\mathrm{EY}}{\mathrm{B}}$ Open Access

\begin{abstract}
The triple-c cartilage tympanoplasty i.e. (composite chondroperichondrial clip) technique was devised by Fernandes in 2003. Objectives: The objective of our case series was to assess the success rate and efficacy of the triple-c cartilage tympanoplasty by transcanal approach. Study Design: A retrospective analysis of patients subjected to the technique was conducted. Methods: 20 cases who met the inclusion criteria were assessed by otomicroscopy and pure tone audiometry before and 2 months after the surgery. Results: All patients had complete take-up of the graft and a hearing improvement which was statistically significant. Conclusions: Thus the triple-c technique provides an effective method of closing nonmarginal perforations of the tympanic membrane.
\end{abstract}

\section{Keywords}

Triple-c, Cartilage, Tympanoplasty

\section{Introduction}

Ideal graft material for tympanoplasty has always been a dilema. Heerman was the first to consider temporalis fascia as a grafting material. Storrs successfully employed it thereafter [1]. The concept of grafting tragal cartilage and perichondrium was introduced by Good hill [1].

Tragal cartilage with perichondrium (Figure 1) fulfills all the required qualities of an ideal graft material namely low rejection rate, sufficient quantity, good tensile strength, conductive properties similar to that of tympanic membrane and easy availability.

Fernandes from Newcastle, Australia published the technique of composite chondroperichondrial clip tympanoplasty using the tragal cartilage [2].

In this technique the cartilage-perichondrium graft is both an onlay and underlay graft similar to the butterfly

How to cite this paper: Parelkar, K., Nagle, S., Jagade, M., Thorawade, V., Khairnar, P., Attakil, A., Pandare, M., Nataraj, R., Hanwate, R. and Kar, R. (2015) Triple-c Cartilage Tympanoplasty: Case Series. International Journal of Otolaryngology and Head \& Neck Surgery, 4, 26-31. http://dx.doi.org/10.4236/ijohns.2015.41005 


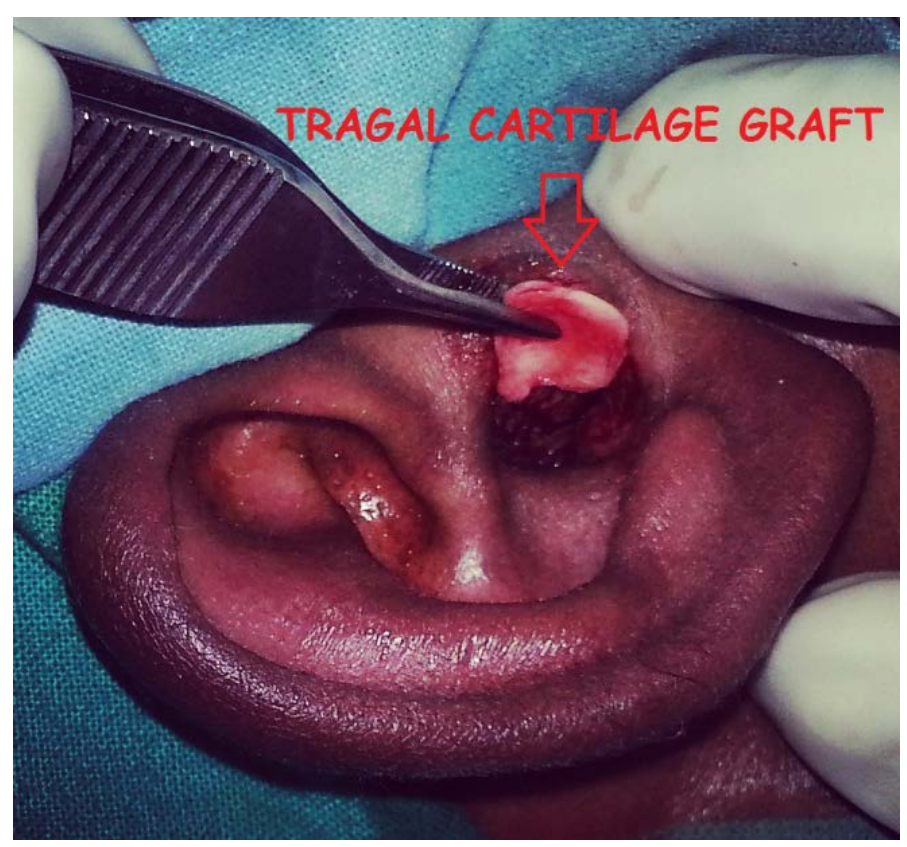

Figure 1. Tragal cartilage with perichondrium being harvested.

technique without its disadvantages. Many cases with small harmless perforations of the ear drum are operated by retroauricular approach using fascia due to the cartilage and onlay phobia. In these cases the triple-c cartilage tympanoplasty by transcanal approach would be a splendid and minimally invasive solution.

The triple-c technique is fairly simple, sutureless and effective method [3] of type-1 tympanoplasty with good patient compliance and reduced hospital stay in our experience as discussed below.

\section{Methodology}

20 cases in the age group of 12 to 50 years with small to moderate sized perforations and a dry ear (for at least 6 months) were selected. Patients with marginal perforations were excluded.

These patients had a hearing loss no greater than $40 \mathrm{db}$ at any frequency on preoperative pure tone audiometry.

All 20 cases underwent meticulous preoperative assessment which included otomicroscopy, pure tone audiometry and routine workup.

Eustachian tube patency was tested by valsalva and methylene blue dye test.

The ossicular status and mobility were assessed by endoscopy through the moderate perforations specially in patients having hearing loss on the higher side.

The graft take-up and the hearing were assessed 2 months postoperatively (Figure 2) with otomicroscopy and pure tone audiometry respectively.

\section{Technique}

1) Transcanal method was used and tragal cartilage with perichondrium on both sides harvested.

2) The perichondrium from the medial side of the graft was removed while that from the lateral side of the graft raised 1 - $2 \mathrm{~mm}$ from all around the margins (Figure 3).

3) The fashioned graft was then slipped through the perforation in a similar way as the lens in its capsule in ophthalmology and dialled in place using a pick.

4) The perichondrium was then gently pulled out from the perforation and spread over the denuded margins in an overlay fashion (Figure 4).

Thus making the cartilage proper as an underlay graft and perichondrium an onlay one, clipping the freshened margins of the perforation. 


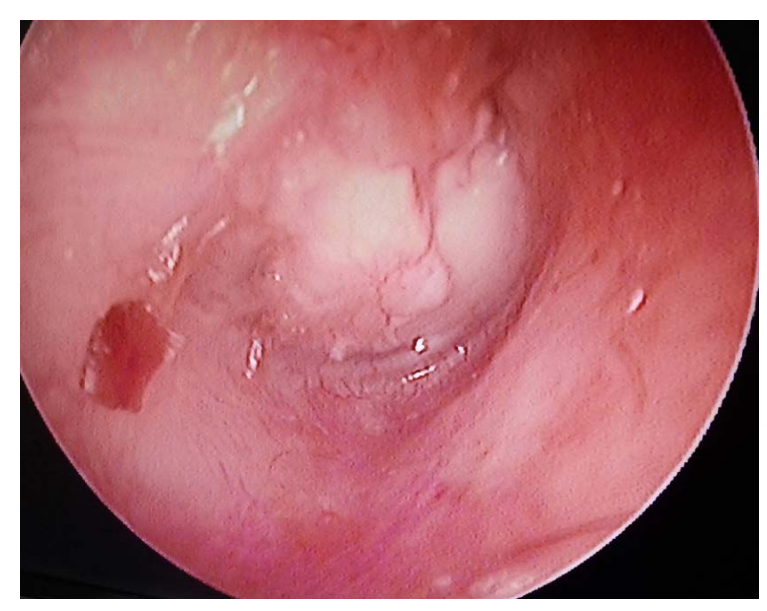

Figure 2. 2 months postoperatively showing take-up of the graft.

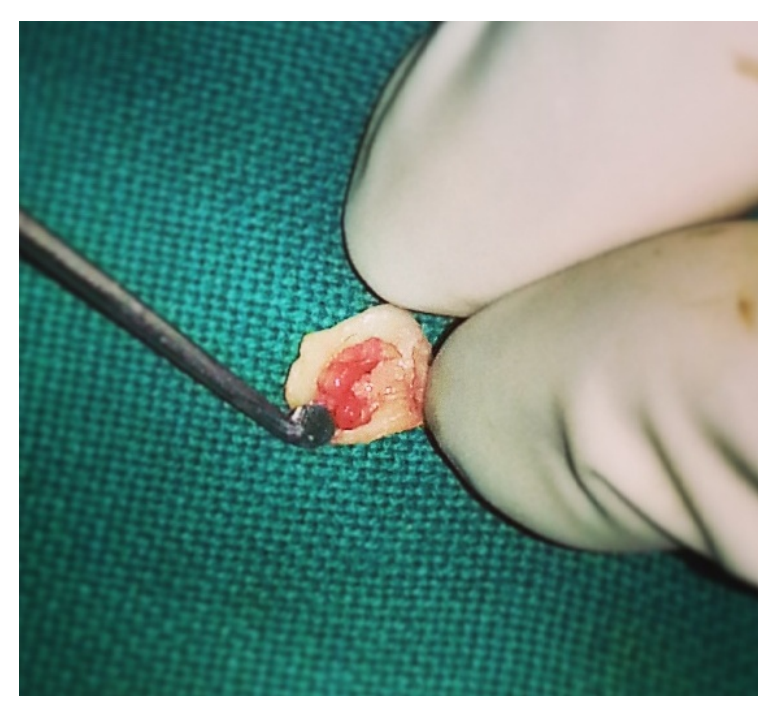

Figure 3. Perichondrium from lateral side raised all along the margins of the cartilage.

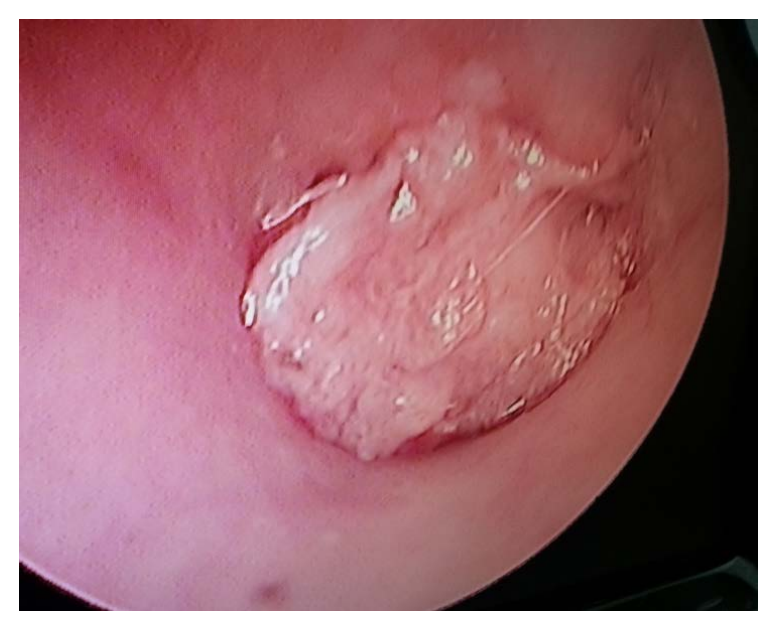

Figure 4. Perichondrium spread in overlay fashion and the cartilage proper placed as an underlay graft. 


\section{Results}

The following table shows the hearing improvement 2 months post-operatively in our case series.

\begin{tabular}{|c|c|c|c|c|c|}
\hline Sr. no. & $\begin{array}{c}\text { Pre-operative } \\
\text { hearing loss }(\mathrm{db})\end{array}$ & $\begin{array}{c}\text { Post-operative hearing } \\
\text { loss (db) }\end{array}$ & Difference & Deviation & Square of deviation \\
\hline 1. & 45 & 30 & -15 & 2.35 & 5.52 \\
\hline 2. & 45 & 25 & -20 & -2.65 & 7.02 \\
\hline 3. & 40 & 23 & -17 & 0.35 & 0.12 \\
\hline 4. & 40 & 20 & -20 & -2.65 & 7.02 \\
\hline 5. & 40 & 20 & -20 & -2.65 & 7.02 \\
\hline 6. & 40 & 20 & -20 & -2.65 & 7.02 \\
\hline 7. & 40 & 20 & -20 & -2.65 & 7.02 \\
\hline 8. & 40 & 25 & -15 & 2.35 & 5.52 \\
\hline 9. & 45 & 25 & -20 & -2.65 & 7.02 \\
\hline 10. & 35 & 20 & -15 & 2.35 & 5.52 \\
\hline 11. & 40 & 25 & -15 & 2.35 & 5.52 \\
\hline 12. & 40 & 25 & -15 & 2.35 & 5.52 \\
\hline 13. & 40 & 25 & -15 & 2.35 & 5.52 \\
\hline 14. & 40 & 20 & -20 & -2.65 & 7.02 \\
\hline 15. & 35 & 20 & -15 & 2.35 & 5.52 \\
\hline 16. & 45 & 25 & -20 & -2.65 & 7.02 \\
\hline 17. & 40 & 20 & -20 & -2.65 & 7.02 \\
\hline 18. & 40 & 25 & -15 & 2.35 & 5.52 \\
\hline 19. & 40 & 25 & -15 & 2.35 & 5.52 \\
\hline 20. & 40 & 25 & -15 & 2.35 & 5.52 \\
\hline
\end{tabular}

Difference Scores Calculations: T-value calculation: $\mathrm{t}=(\mathrm{M}-\mu) / \mathrm{S}_{\mathrm{M}}=(-17.35-0) / 0.56=31.06$; Mean: $-17.35 ; \mu=0 ; \mathrm{S}^{2}=\mathrm{SS} / \mathrm{df}=118.55 /(20-1)=$ 6.24; $\mathrm{S}_{\mathrm{M}}^{2}=\mathrm{S}^{2} / \mathrm{N}=6.24 / 20=0.31 ; \mathrm{S}_{\mathrm{M}}=\sqrt{\mathrm{S}_{\mathrm{M}}^{2}}=\sqrt{0.31}=0.56$; The value of $\mathrm{t}$ is -31.062793 . The value of $\mathrm{p}$ is $<0.00001$. The result is significant at $\mathrm{p} \leq 0.05$.

\section{Discussion}

Tympanic membrane perforations significantly impair the quality of life for millions of patients [4].

Though temporalis fascia is the most commonly used graft material it should be noted that cartilage contributes minimally to an inflammatory tissue reaction and is well incorporated with tympanic membrane layers; it also provides firm support to prevent retraction. The main advantage of the cartilage graft has been thought to be its very low metabolic rate. It receives its nutrients by diffusion, is easy to work with because it is pliable, and it can resist deformation from pressure variations [5].

The perceived disadvantage of the cartilage graft is that it creates an opaque tympanic membrane, which could potentially hide a residual cholesteatoma [6].

Mirko Tos described 23 known cartilage tympanoplasty methods to reconstruct the eardrum and proposed a classification into six main groups [7]. The triple-c and the butterfly technique belong to group-F as per this classification.

Eavey was the first to describe the butterfly cartilage inlay grafting technique. The edges of the cartilage perichondrial composite graft curve out like butterfly wings when the edge is split [8]. Though an attractive technique there maybe problems with epithelisation of the graft and accumulation of keratin under the wing of the cartilage causing displacement of the graft similar to a grommet. In the triple-c technique we did not face such issues. 
When partial thickness cartilage with perichondrium on the lateral aspect alone is fashioned, there is curling of the cartilage possibly due to the pull by the perichondrium, this can be addressed to a certain amount by the triple-c technique as here the perichondrium is raised all along the margins of the cartilage.

There is very limited data regarding curling of the cartilage, four incisions of the perichondrium "the anticurling incisions" have been described by Mirko Tos but a systematic study is still required to validate them.

Using a normal tympanic membrane as a reference, Zahnert et al. noted that a cartilage plate with a thickness of less than $0.5 \mathrm{~mm}$ gave the least acoustic transfer loss [9]. Though recent studies show no difference in hearing results between the full thickness and partial thickness grafts.

Also histomorphological studies of cartilage grafts (Hitari, 2006) have shown that there is wide replacement of the chondrocytes by fibrous tissue and loss of lipid vacuoles over time which makes the cartilage graft more homogenous in nature. This transfers the acoustic energy better than normal cartilage.

In 2004, Gierek et al. [10] performed 112 cases with cartilage and 30 cases with temporalis fascia. They observed that there was no significant hearing difference between the two groups. Couloinger et al. [11] observed 59 cartilage graft tympanoplasties and 20 temporalis fascia graft tympanoplasties in 2005 and they reported no postoperative hearing difference between the two groups.

Hence even though temporalis fascia is the current choice, cartilage grafts with minimally invasive techniques such as the triple-c technique may replace fascia for small to moderate sized non-marginal perforations.

Also in near future endoscopic approach for this technique will be in vogue. Otoendoscopy gives the surgeon a panoramic view and helps in visualization of many hidden areas of the middle ear [12], it may modify this novel technique even further.

\section{Conclusions}

In our experience the composite chondroperichondrial "clip” tympanoplasty using the tragal cartilage and transcanal approach has the following advantages:

- Minimally invasive

- Sutureless

- Reduced operative time

- Excellent hearing improvement

- Assurance of graft take-up

- Better patient compliance and reduced hospital stay

Though a highly efficacious technique, comparative studies between the triple-c and the butterfly technique are necessary. Also long term follow-up of cases managed with this technique and studies regarding the fate of cartilage graft would help us understand cartilage tympanoplasty in greater depths.

\section{References}

[1] Glasscock, M.E. and Shambaugh, G.E. Surgery of the Ear 5th Edition Pathology and Clinical Course of Inflammatory Disease of the Middle Ear. Vol. 21, 428-429.

[2] Fernandes, S.V. (2003) Composite Chondroperichondrial Clip Tympanoplasty: The Triple-C Technique. Otolaryngology_Head and Neck Surgery: Official Journal of American Academy of Otolaryngology-Head and Neck Surgery, 128, 267-267. http://dx.doi.org/10.1067/mhn.2003.88

[3] Ahmed, S., Raza, N., Ullah, S. and Shabbir, A. (2013) Chondroperichondrial Clip Myringoplasty: A New Technique for Closure of Tympanic Membrane Perforations. The Journal of Laryngology \& Otology, 127, 562-567. http://dx.doi.org/10.1017/S0022215113000595

[4] Rahman, A. (2007) Healing of Tympanic Membrane Perforation: An Experimental Study. Karolinska Institute and University Hospital, Stockhole.

[5] Yung, M. (2008) Cartilage Tympanoplasty: Literature Review. The Journal of Laryngology \& Otology, 122, 663-672.

[6] Ghanem, M.A., Monroy, A., Alizadeh, F.S., Nicolau, Y. and Eavey, R.D. (2006) Butterfly Cartilage Graft Inlay Tympanoplasty for Large Perforations. Laryngoscope, 116, 1813-1816. http://dx.doi.org/10.1097/01.mlg.0000231742.11048.ed

[7] Tos, M. (2009) Cartilage Tympanoplasty: Classifications of Methods_-Techniques—Results. Edition I, Thieme.

[8] Eavey, R.D. (1998) Inlay Tympanoplasty: Cartilage Butterfly Technique. Laryngoscope, 108, 657-661. http://dx.doi.org/10.1097/00005537-199805000-00006 
[9] Zahnert, T., Huttenbrink, K.-B., Murbe, D. and Bornitz, M. (2000) Experimental Investigations of the Use of Cartilage in Tympanic Membrane Reconstruction. American Journal of Otolaryngology, 21, 322-328. http://dx.doi.org/10.1016/S0196-0709(00)80039-3

[10] Gierek, T., Slaska-Kaspera, A., Majzel, K. and Klimczak-Gotqb, L. (2004) Results of Myringoplasty and Type I Tympanoplasty with the Use of Fascia, Cartilage and Perichondrium Grafts. Otolaryngologia Polska, 3, 529-533. (In Polish)

[11] Couloigner, V., Baculard, F., El Bakkouri, W., Viala, P., Francois, M., Narcy, P., et al. (2005) Inlay Butterfly Cartilage Tympanoplasty in Children. Ontology Neurotology, 26, 247-251. http://dx.doi.org/10.1097/00129492-200503000-00020

[12] Harugop, A.S., Mudhol, R.S. and Godhi, R.A. (2008) A Comparative Study of Endoscope Assisted Myringoplasty and Microscope Assisted Myringoplasty. Indian Journal of Otolaryngology and Head Neck Surgery, 60, 299-302. http://dx.doi.org/10.1007/s12070-008-0099-5 
Scientific Research Publishing (SCIRP) is one of the largest Open Access journal publishers. It is currently publishing more than 200 open access, online, peer-reviewed journals covering a wide range of academic disciplines. SCIRP serves the worldwide academic communities and contributes to the progress and application of science with its publication.

Other selected journals from SCIRP are listed as below. Submit your manuscript to us via either submit@scirp.org or Online Submission Portal.
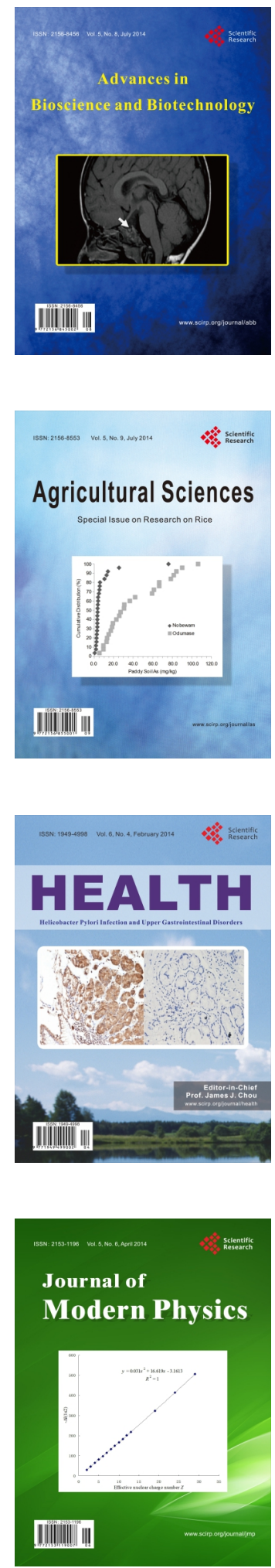
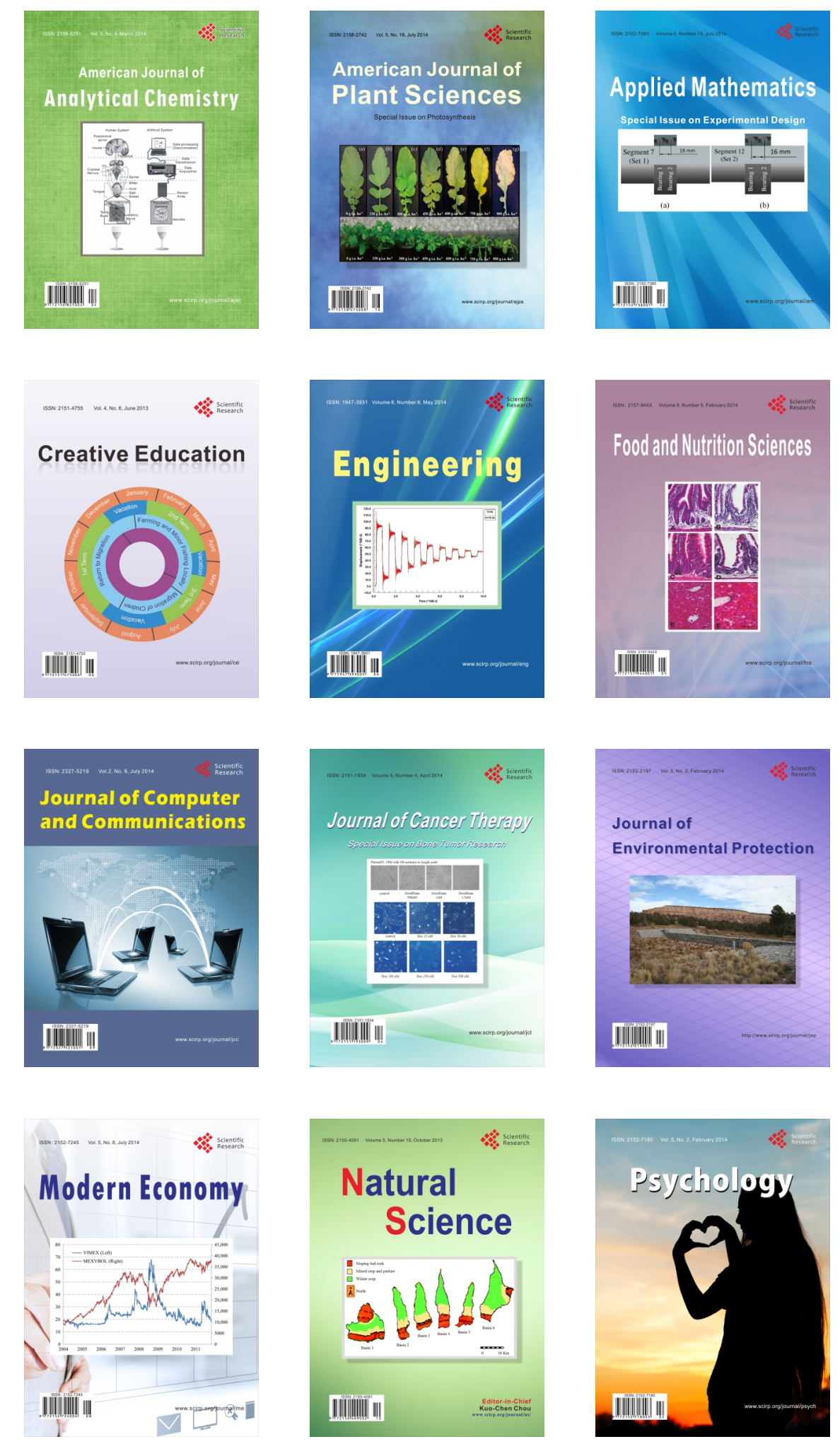